\title{
Hepatocellular cancer selection systems and liver transplantation: from the tower of babel to an ideal comprehensive score
}

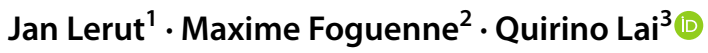 \\ Received: 14 February 2021 / Accepted: 3 May 2021 / Published online: 18 May 2021 \\ (c) The Author(s) 2021
}

\begin{abstract}
The Milan criteria (MC) remain the cornerstone for the selection of patients with hepatocellular cancer (HCC) to be listed for liver transplantation (LT). Recently, several expanded criteria have been proposed to increase the transplantability of HCC patients without compromising their (oncologic) outcome. This paper aims to systematically review the different reported HCC-LT selection systems looking thereby at their ability to increase the number of transplantable patients and the overall survival and oncological outcome. A systematic review of the literature covering the period 1993 (date of the first reported HCC-LT selection system)-2021 identified 59 different inclusion criteria of HCC for LT. Among the 59 studies reporting HCC-LT selection systems, 15 (28.3\%) were exclusively based on morphological aspects of the tumor; $29(54.7 \%)$ included biologic, seven (13.2\%) radiological, and two (3.8\%) only included pathological tumor features. Overall, $31 \%$ more patients could be transplanted when adhering to the new HCC-LT selection systems. Despite the increased number of LT, 5-year patient and disease-free survival rates were similar between MC-IN and MC-OUT/new HCC-LT-IN criteria. A careful extension of the inclusion criteria should allow many more patients to access a potentially curative LT without compromising their outcome. The development of a widely accepted "comprehensive" HCC-LT Score able to offer a fair chance of justified transplantation to more patients should become a priority within the liver transplant community. Further studies are needed to develop internationally accepted, expanded selection criteria for liver transplantation of HCC patients.
\end{abstract}

Keywords Liver transplantation $\cdot$ Hepatocellular cancer $\cdot$ Score $\cdot$ Selection criteria $\cdot$ Recurrent tumor

$\begin{array}{ll}\text { Abbreviations } \\ \text { AFP } & \text { Alpha-fetoprotein } \\ \text { CI } & \text { Confidence intervals } \\ \text { DFS } & \text { Disease-free survival } \\ \text { HCC } & \text { Hepatocellular cancer } \\ \text { I2 } & \text { Higgins statistic squared } \\ \text { LDLT } & \text { Living donor liver transplantation } \\ \text { LT } & \text { Liver transplantation } \\ \text { MC } & \text { Milan criteria }\end{array}$

Quirino Lai

lai.quirino@libero.it

Jan Lerut

jan.lerut@uclouvain.be

1 Institute for Experimental and Clinical Research (IREC), Université Catholique de Louvain (UCL), Avenue Hippocrates 55, 1200 Brussels, Belgium

2 University Hospitals Saint-Luc Université Catholique de Louvain (UCL), Brussels, Belgium

3 General Surgery and Organ Transplantation Unit, Sapienza University of Rome, Rome, Italy
mRECIST Modified-response evaluation criteria in solid tumors

NLR Neutrophil-to-lymphocyte ratio

OR Odds ratio

PIVKA-II Protein induced by vitamin K absence-II

PLR Platelet-to-lymphocyte ratio

PS Patient survival

UCSF University of California, San Francisco

\section{Introduction}

Thomas Starzl designed liver transplantation (LT) to treat unresectable primary and secondary hepatobiliary tumors $[1,2]$. The first 'successful' LT was performed on July 23, 1967 , in a child presenting with a large hepatocellular cancer (HCC) in the context of biliary atresia. The child died after 400 days, during which time she underwent many reinterventions to treat both thoracic and abdominal tumor recurrences. Due to the lack of selection criteria, the concept of LT as the primary treatment of hepatobiliary malignancies 
was rapidly challenged because of the prohibitively high incidence of tumor recurrence $[2,3]$. The 'oncological pendulum' reversed in the nineties. The indication for LT moved from large multifocal lesions to a more limited tumor burden. A tumor load restricted to $\leq$ three tumors having a diameter $\leq 3 \mathrm{~cm}$ (Paris criteria) or one tumor $\leq 5 \mathrm{~cm}$ (Milan criteria, MC) resulted in 5-year disease-free survival (DFS) rates of $70-80 \%[4,5]$. The MC became the international gold standard to select HCC patients for LT [6-8]. However, after some years of stabilized practice, it became clear that the MC were too strict, denying access for many patients to potentially curative therapy. Many Western teams worked at a cautious extension of the inclusion criteria. Conversely, many Eastern ones adopted a much more aggressive attitude fostered by the explosive development of living-donor-liver transplantation (LDLT) [9]. The search for 'the ideal' score was launched to give as many patients as possible access to a potentially curative oncological procedure without compromising outcomes. However, the co-existence of multiple scoring systems explains the heterogeneous treatment of HCC, leading to difficulties when interpreting short- and long-term outcomes, and access to LT varies widely among countries, continents, and allocation organizations.

This paper aims to systematically review the different HCC-LT selection systems developed, with the intent to investigate their impact in terms of access to LT without compromising overall survival and oncological results. Using the available data, a meta-analysis was also done to investigate the post-transplant recurrence rates reported using the MC vs. the expanded selection criteria.

\section{Materials and methods}

\section{Search sources and study design}

A systematic review of the published literature on the different HCC-LT selection systems developed was undertaken. The search strategy was performed following the preferred reporting items for systemic reviews and meta-analysis (PRISMA) guidelines [10].

The specific research question formulated in the present study included the following PICO components:

Patient: patient with a confirmed HCC undergoing a LT;

Intervention: LT adopting an expanded HCC-LT selection system;

Comparison: LT adopting a standard selection approach (typically, the MC);

Outcome: patient death and/or tumor recurrence.

A search of the PubMed and Cochrane Central Register of Controlled Trials Databases was conducted using the following terms: ("liver transplant*"[Title/Abstract] OR "living donor liver transplant*"[Title/Abstract]) OR "living donor" AND ("criteria"[Title/Abstract] OR "score"[Title/ Abstract] OR "model"[Title/Abstract]) AND ("HCC"[Title/ Abstract] OR "hepatocellular carcinoma"[Title/Abstract] OR "hepatocellular cancer"[Title/Abstract]) AND ("1993/01/01"[PDAT]: "2021/03/14"[PDAT]).

The search period was from "1993/01/01" to "2021/03/14". The systematic review considered only English studies that included human patients. The start of the search period corresponded to the first publication of an HCC-LT selection system by the Bismuth group [4].

Published reports were excluded based on several criteria: (a) data on animal models; (b) lacked enough clinical details; (c) had non-primary source data (e.g., review articles, nonclinical studies, letters to the editor, expert opinions, and conference summaries). In studies originating from the same center, possible overlapping of clinical cases was examined, and the most informative study was considered eligible for inclusion.

\section{Data extraction and definitions}

Following a full-text review of the eligible studies, two independent authors (MF and JL) performed the data extraction and crosschecked all outcomes. When selecting articles and data extraction, potential discrepancies were resolved following a consensus with a third reviewer (QL). Collected data included: first author of the publication, reference number, center, year of publication, type of selection system (based on morphological, biological, radiological, or pathological aspects), number of cases, number of patients within the new selection system, number of cases within $\mathrm{MC}$, number of patients exceeding $\mathrm{MC}$, additive number and increased percentage of LT cases compared with the MC, 5 -year overall and disease-free survival rates in new criteriaIN, MC-OUT/new criteria-IN, and new criteria-OUT cases and finally percentage of living donor LT.

As already reported, we stratified the selection systems identified in four groups according to the characteristics of the variables composing the scores. In detail: (a) "morphological" systems were based only on the radiology-derived tumor variables (i.e., number and dimensions); (b) "biological" systems also included biological markers derived from the blood tests; (c) "radiological" systems also included variables derived from the post-locoregional therapy response or the radiology-related tumor activity (i.e., PET avidity); and, (d) "histological" scores also included parameters connected with pre-LT biopsies.

\section{Quality assessment}

Selected studies were systematically reviewed with the intent to identify potential sources of bias. The papers' quality was 
assessed using the Risk of Bias In Non-randomized Studies of Interventions (ROBINS-I) tool [11].

\section{Statistical analysis}

The meta-analysis was performed using OpenMetaAnalyst. The statistical heterogeneity was evaluated with the Higgins statistic squared $\left(I^{2}\right) . I^{2}$ value was considered indicative of heterogeneity: low $=0-25 \% ; 26-50 \%=$ moderate $\geq 51 \%=$ high. In the case of low-to-moderate $(0-50 \%)$ heterogeneity, a fixed-effects model was used. The random-effects model was used when high heterogeneity was reported. The odds ratio (OR) and $95 \%$ confidence intervals (95\% CI) were reported. A $P$ value $<0.05$ was considered indicative of statistical significance.

\section{Results}

\section{Search results and study characteristics}

The PRISMA flow diagram schematically depicts the article selection process (Fig. 1). Among the 2898 articles screened, 59 studies reporting HCC-LT selection systems were identified $[4,5,7,8,12-66]$.

The variables adopted for constructing the selection systems and selecting HCC patients for LT were as follows: 15 (25.4\%) were exclusively based on morphological tumor characteristics; $34(57.6 \%)$ on biological characteristics either alone or in combination with morphological features, eight $(13.6 \%)$ on radiological features, and two (3.4\%), on pathological characteristics only. More detailed information about the different variables used to construct a new selection system is displayed in Table $1[4,5,7$, 12-66].

As for the period of publication, only two studies (3.4\%) were published before 2000, [4, 5] 21 (35.6\%) during the decade 2000-2009, and $36(61.0 \%)$ during the decade 2010-2021. Interestingly, all but one study based only on morphological tumor characteristics was published before 2010 [23]. The geographical distribution of the articles was as follows: Asia 30 (50.8\%), Europe 17 (28.8\%), and North America 12 (20.4\%). In 22 (37.3\%) papers, HCC-LT selection systems were developed in the field of LDLT. In $47(79.7 \%)$ studies, the MC status was reported, thereby comparing the respective proposed new selection systems. According to the data reported, the MC status was estimable in only one $(1.7 \%)$ report.

\section{Qualitative assessment of the included studies}

Results from the qualitative assessment of the included studies are shown in Fig. 2. Overall, 9 (15.3\%) studies presented an unclear risk of bias due to the absence of data from a comparative group; in $5(8.5 \%)$ studies, data
Fig. 1 PRISMA flow diagram showing the article selection process

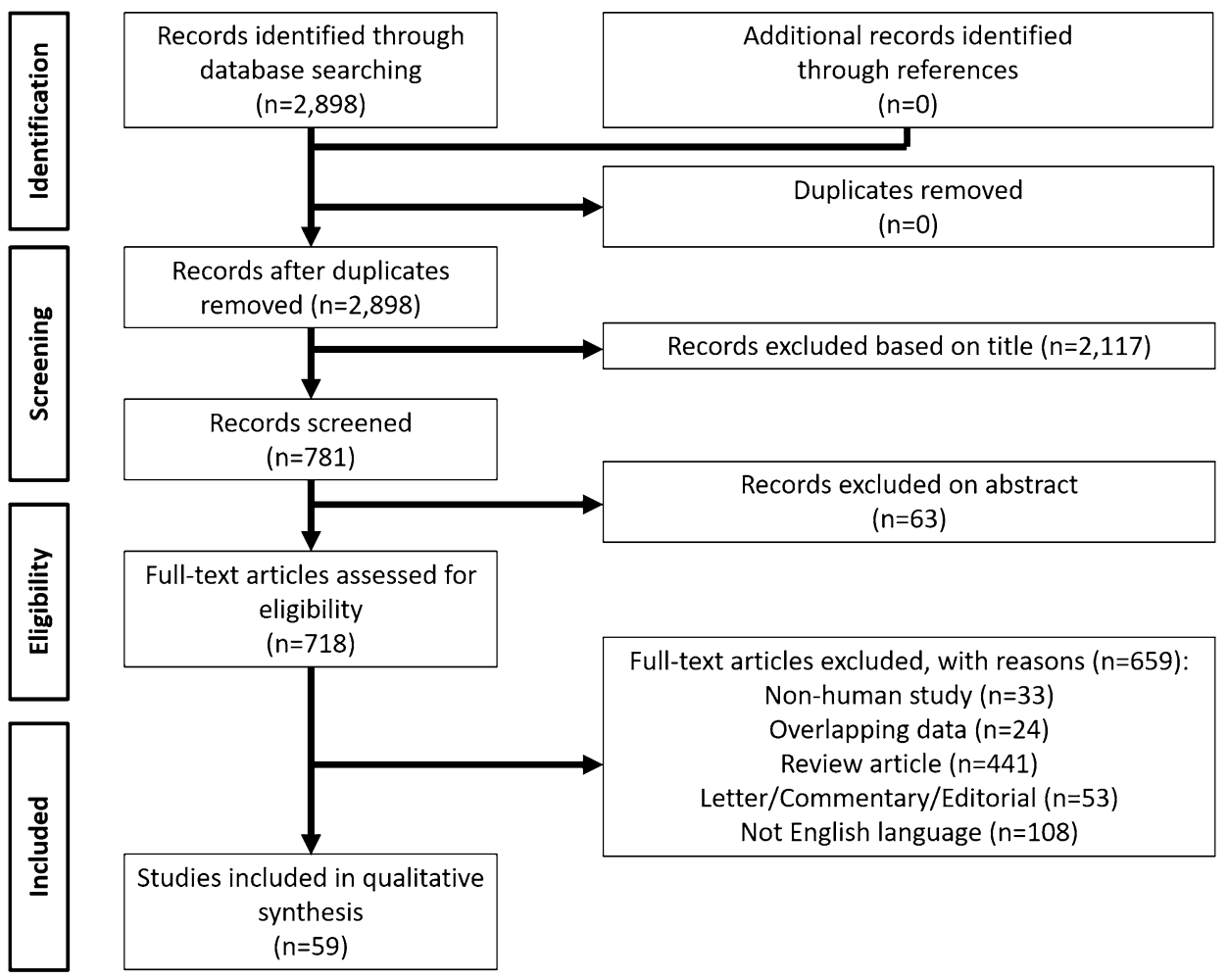




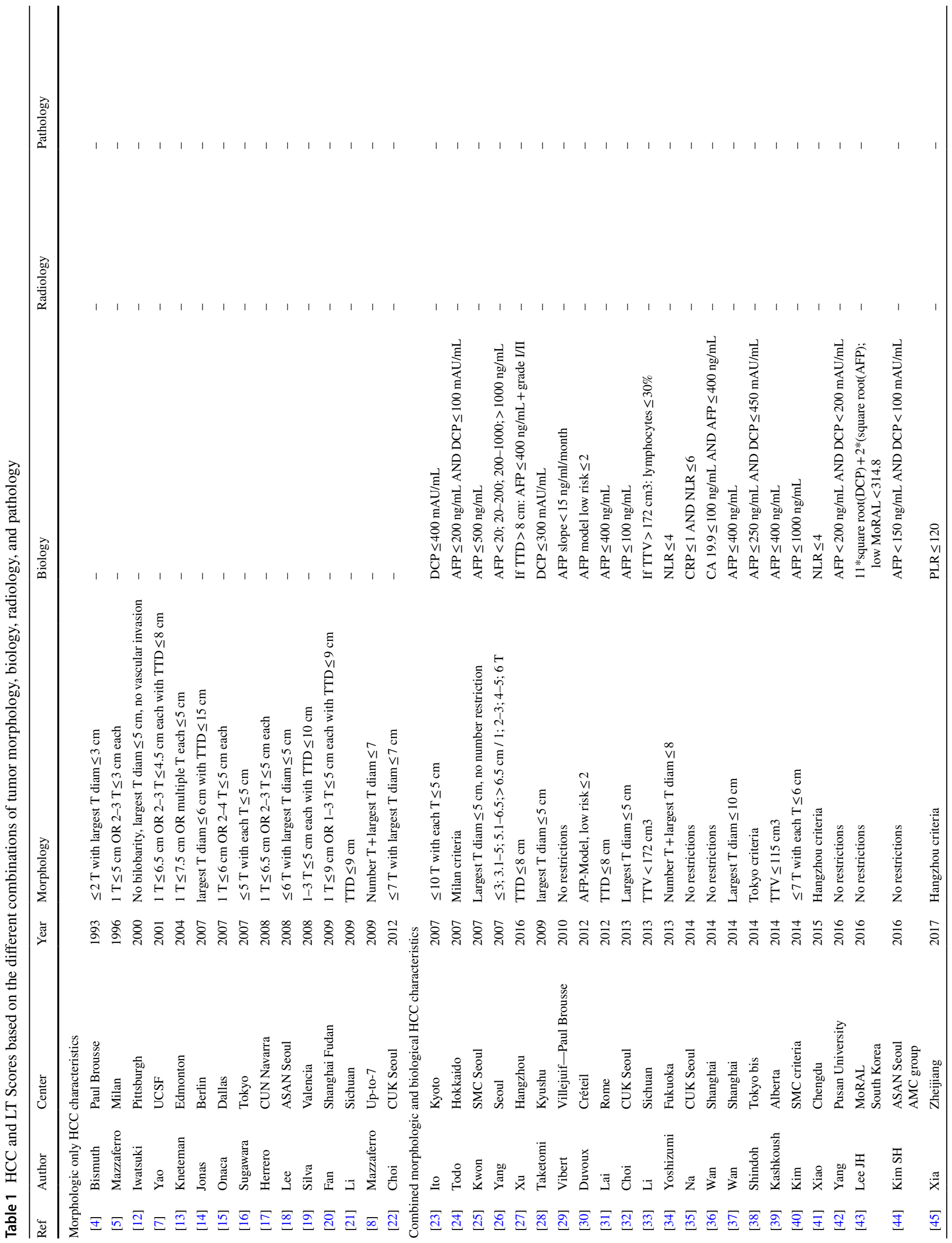




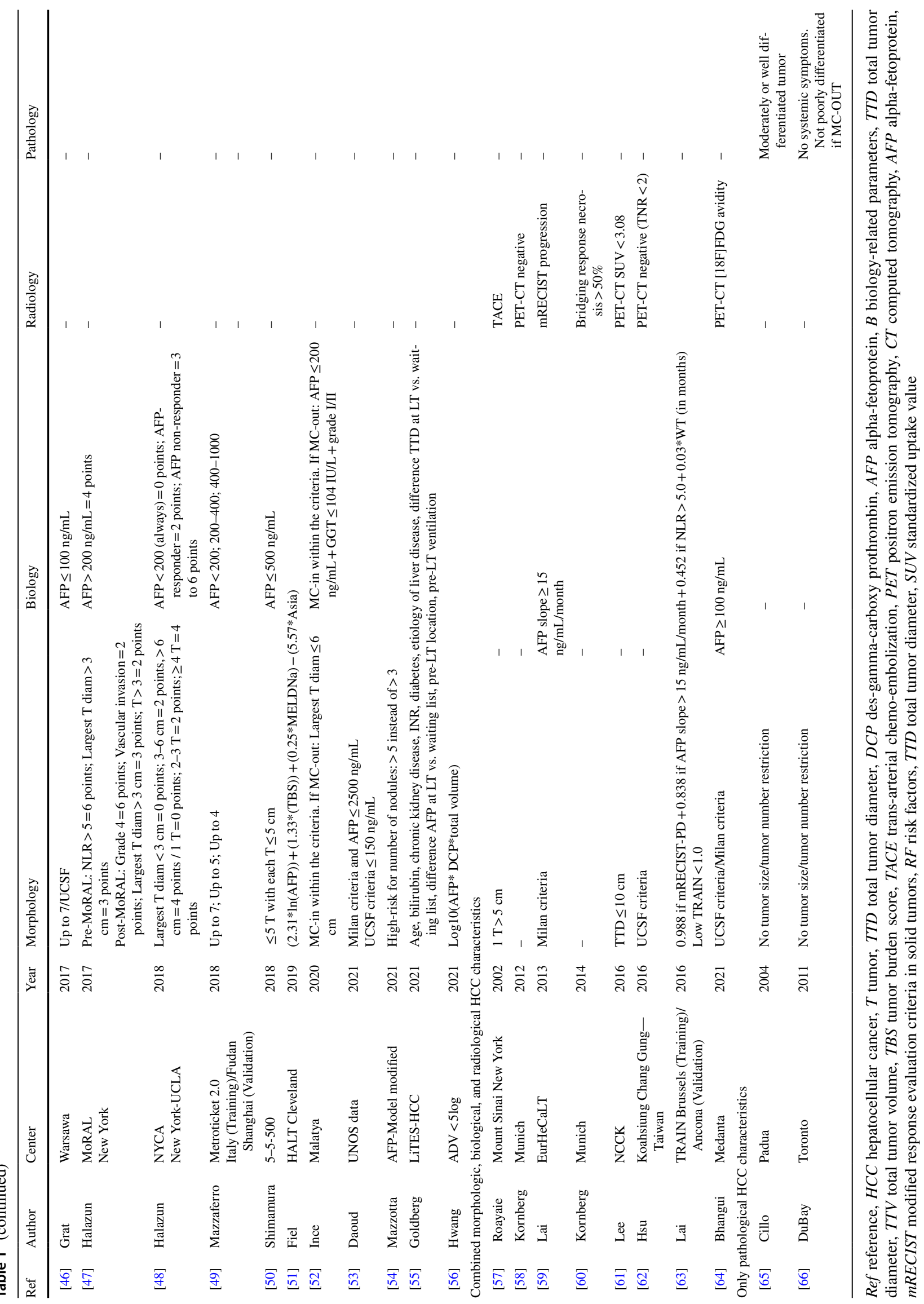




\begin{tabular}{|c|c|c|c|c|c|c|c|c|}
\hline \multicolumn{9}{|c|}{ MORPHOLOGY } \\
\hline Bismuth & 1993 & & & & & & & \\
\hline Mazzaferro & 1996 & & & & & & & \\
\hline Iwatsuki & 2000 & & & & & & & \\
\hline Yao & 2001 & & & & & & & \\
\hline Kneteman & 2004 & & & & & & & \\
\hline Jonas & 2007 & & & & & & & \\
\hline Onaca & 2007 & & & & & & & \\
\hline Sugawara & 2007 & & & & & & & \\
\hline Herrero & 2008 & & & & & & & \\
\hline Lee & 2008 & & & & & & & \\
\hline Silva & 2008 & & & & & & & \\
\hline Fan & 2009 & & & & & & & \\
\hline $\mathrm{Li}$ & 2009 & & & & & & & \\
\hline Mazzaferro & 2009 & & & & & & & \\
\hline Choi & 2012 & & & & & & & \\
\hline \multicolumn{9}{|c|}{ RADIOLOGY } \\
\hline Roayaie & 2002 & & & & & & & \\
\hline Kornberg & 2012 & & & & & & & \\
\hline Lai & 2013 & & & & & & & \\
\hline Kornberg & 2014 & & & & & & & \\
\hline Lee & 2016 & & & & & & & \\
\hline Hsu & 2016 & & & & & & & \\
\hline Lai & 2016 & & & & & & & \\
\hline \multicolumn{9}{|c|}{ PATHOLOGY } \\
\hline Cillo & 2004 & & & & & & & \\
\hline DuBay & 2011 & & & & & & & \\
\hline & & 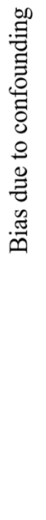 & 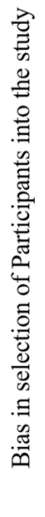 & 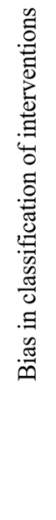 & 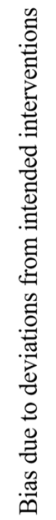 & 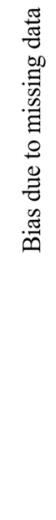 & 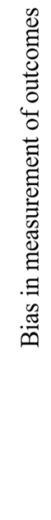 & 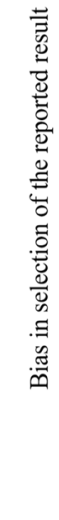 \\
\hline
\end{tabular}

\begin{tabular}{|c|c|c|c|c|c|c|c|c|}
\hline \multicolumn{9}{|c|}{ BIOLOGY } \\
\hline Ito & 2007 & & & & & & & \\
\hline Todo & 2007 & & & & & & & \\
\hline Kwon & 2007 & & & & & & & \\
\hline Yang & 2007 & & & & & & & \\
\hline Xiao & 2016 & & & & & & & \\
\hline Taketomi & 2009 & & & & & & & \\
\hline Vibert & 2010 & & & & & & & \\
\hline Duvoux & 2012 & & & & & & & \\
\hline Lai & 2012 & & & & & & & \\
\hline Choi & 2013 & & & & & & & \\
\hline $\mathrm{Li}$ & 2013 & & & & & & & \\
\hline Yoshizumi & 2013 & & & & & & & \\
\hline $\mathrm{Na}$ & 2014 & & & & & & & \\
\hline Wan & 2014 & & & & & & & \\
\hline Wan & 2014 & & & & & & & \\
\hline Shindoh & 2014 & & & & & & & \\
\hline Kashkoush & 2014 & & & & & & & \\
\hline Kim & 2014 & & & & & & & \\
\hline Xiao & 2015 & & & & & & & \\
\hline Yang & 2016 & & & & & & & \\
\hline Lee JH & 2016 & & & & & & & \\
\hline $\mathrm{Kim} \mathrm{SH}$ & 2016 & & & & & & & \\
\hline $\mathrm{Xia}$ & 2017 & & & & & & & \\
\hline Grat & 2017 & & & & & & & \\
\hline Halazun & 2017 & & & & & & & \\
\hline Halazun & 2018 & & & & & & & \\
\hline Mazzaferro & 2018 & & & & & & & \\
\hline Shimamura & 2018 & & & & & & & \\
\hline Fiel & 2019 & & & & & & & \\
\hline Ince & 2020 & & & & & & & \\
\hline Daoud & 2021 & & & & & & & \\
\hline Mazzotta & 2021 & & & & & & & \\
\hline Goldberg & 2021 & & & & & & & \\
\hline Hwang & 2021 & & & & & & & \\
\hline of bias & & 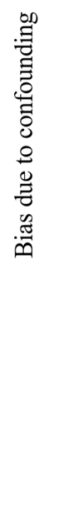 & 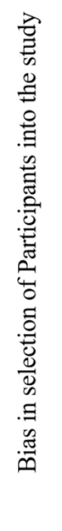 & 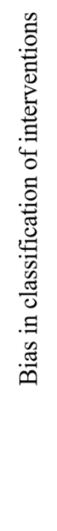 & 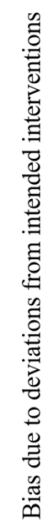 & 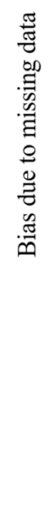 & 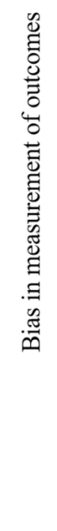 & 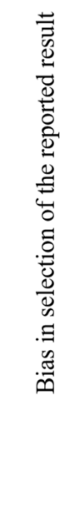 \\
\hline
\end{tabular}

Fig. 2 ROBINS-I qualitative assessment of the included studies 
comparing the outcome of the proposed new selection system with a comparative one were incompletely reported, leading to a potentially high risk of bias.

\section{Review of the eligible studies: the 'tower of Babel' of the selection systems}

Data concerning the results observed in the analyzed selection systems are displayed in Table 2 [4, 5, 7, 8, 12-66].

When considering the $48(81.4 \%)$ studies in which sufficient information was available about the MC status, a total of 20,409 cases were reported, 14,453 of them met the new criteria, and 11,189 were MC-IN.

Overall, a total number of 3353 new criteria-IN/MCOUT cases were reported leading to a $16 \%$ increase of transplanted HCC patients. Apart from two reports [19, 58], all proposed expanded selection systems aimed to widen the inclusion criteria. This intent led to an increase in transplanted patients from 2 to $62 \%$ compared with the MC. (Table 2 and Fig. 3).

Despite the increased number of transplants, the results were only moderately compromised. Interestingly, if the tumor load was within the respective new criteria, 5-year patient survival rates were always superior to 50\% (range: 62-90\%) (Table 2 and Fig. 4). When adhering to the new criteria, excellent 5-year DFS rates were also obtained. Conversely, DFS dropped each time below 50\% if the new selection system was overruled (Table 2 and Fig. 5).

\section{Meta-analysis for the post-transplant recurrence}

Only seventeen papers reported the post-transplant recurrence data required to perform a meta-analysis to compare the $\mathrm{MC}$ vs. the expanded criteria $[13,14,16-18,20,23$, $28,30,32,39,42,46,58,60,65,66]$. When the papers were investigated, no heterogeneity was reported $\left(I^{2}=0\right.$, $P=0.857$ ). A total of 1834 patients meeting the MC (205 recurrences, $11.2 \%$ ) were compared with 2360 patients meeting the different proposed expanded selection systems (268 recurrences, $11.4 \%$ ). No statistical significance was reported between the two groups $(\mathrm{OR}=1.006,95 \% \mathrm{CI}=0.827-1.224$; $P=0.951)$, although a $+28.7 \%$ of transplantable cases was observed using the expanded criteria (Fig. 6).

\section{Discussion}

The data observed in the present systematic review confirm that a careful extension of the inclusion criteria may allow many patients to access a potentially curative LT without seriously compromising the outcome.
The first HCC-LT selection system was 'officially' born in 1996 when Mazzaferro proposed the MC, achieving a 4-year DFS rate of $92 \%$ [5]. Despite the low number of patients reported $(n=48)$, the retrospective design of the study, and the absence of a control group, the MC still rule access of patients to transplant waiting lists more than 30 years later.

MC represent a very efficacious system for selecting HCC patients waiting for LT thanks to its super-selective ability. This is probably the main reason why the MC remain the most valuable benchmark considered in the setting of LT oncology, even in the presence of a large number of studies considering other more sophisticated parameters. However, the strength of the MC contemporaneously represents its weakness: in fact, the super-selection of the MC excludes a too high number of potentially transplantable patients from a curative strategy.

In 2001, the University of California San Francisco (UCSF) group was the first to challenge the MC. Similar survival rates were obtained using their new criteria, the critical difference being that $20 \%$ more patients were able to access a curative LT [7]. Up to now, 59 different HCC scoring systems have been proposed in the setting of HCC and LT [4, 5, 7, 8, 12-66].

All the criteria "extending" the MC can be grouped under the "Metroticket" definition again introduced by the Milan group: the further the trip (namely, the larger the tumor burden), the more expensive the ticket (namely, the higher the post-LT recurrence rate) [8].

Initially, the extension of inclusion criteria for LT was exclusively based on morphological criteria, namely tumor number and diameter [4, 5, 7, 8, 12-22]. In 2007, the Kyoto group [23] for the first time demonstrated that the morphology-alone selection approach was overruled by two fundamental principles of modern oncology, namely the necessity to a) combine tumor morphology and biology and b) evaluate the response to neo-adjuvant therapies to address tumor aggressiveness and behavior [23-66]. The Kyoto group showed that a successful LT could be achieved in patients harboring up to ten tumors on the condition that the tumor marker Protein Induced by Vitamin K Absence-II (PIVKAII) was $<400 \mathrm{mAU} / \mathrm{mL}$ [23].

Other Asian groups elaborated on this concept during the same period by introducing alpha-fetoprotein (AFP) levels in their selection systems [24-26]. Several Japanese and South-Korean centers raised AFP and PIVKAII sensitivity by contemporaneously using these markers $[24,38,42-44,56]$. Also centers from Western countries progressively introduced AFP to select HCC patients, with cut-off levels ranging from 100 to $2,500 \mathrm{ng} / \mathrm{mL}[30,31$, 39, 46-49, 51, 53-55]. Later, inflammatory markers such as neutrophil- (NLR) and platelet-to-lymphocyte (PLR) ratios were added for further refinement [33-35, 41, 45, 


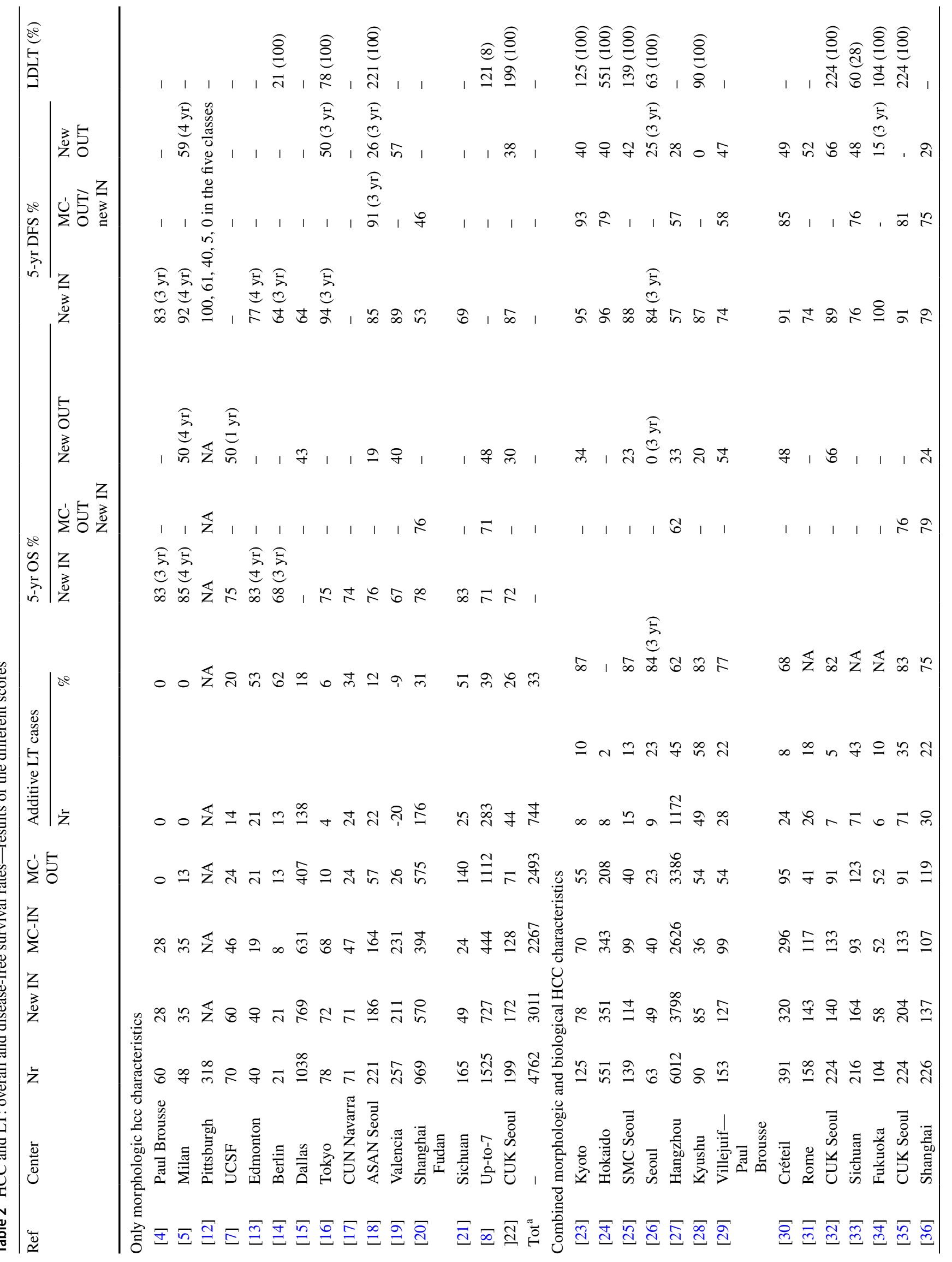




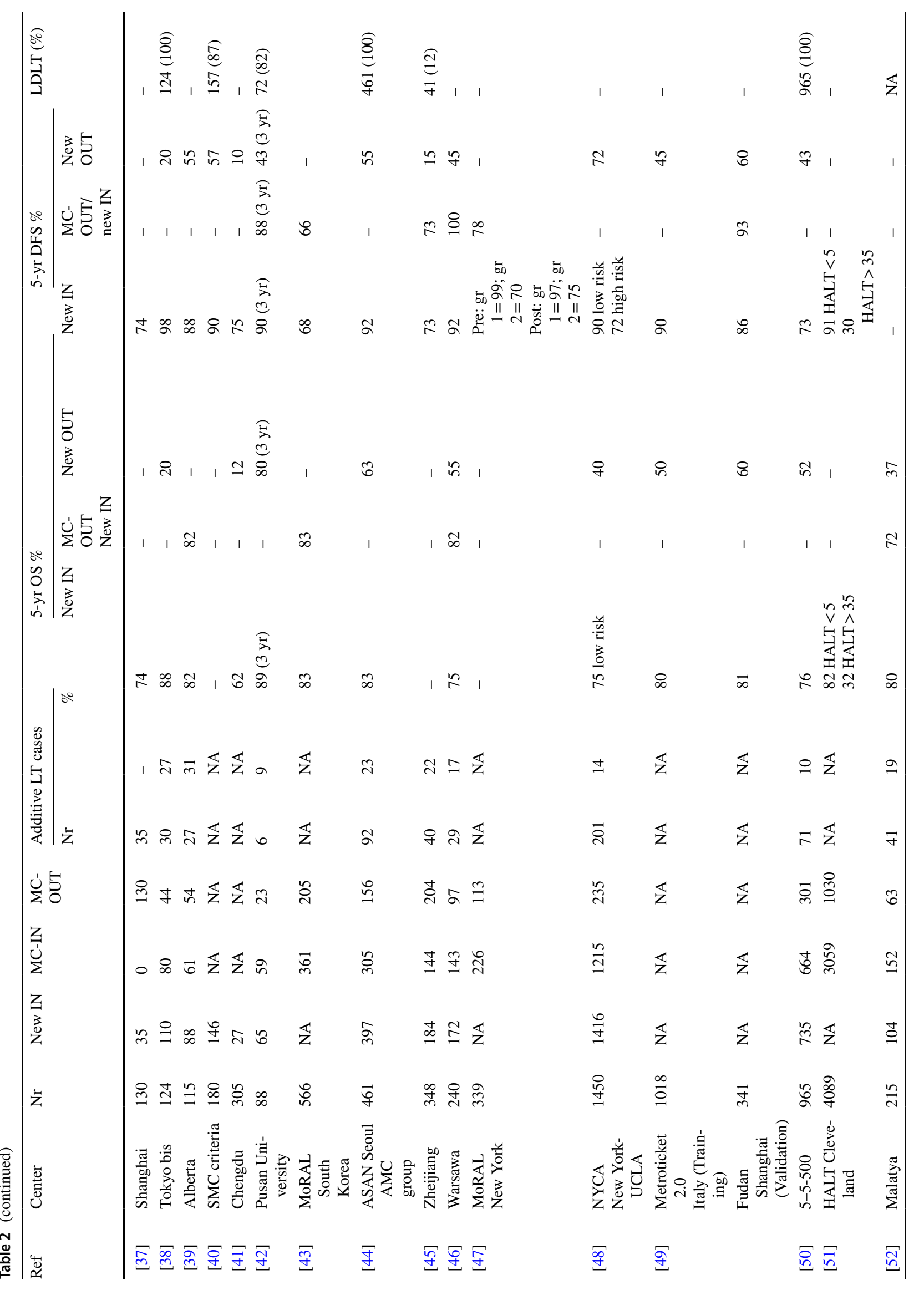




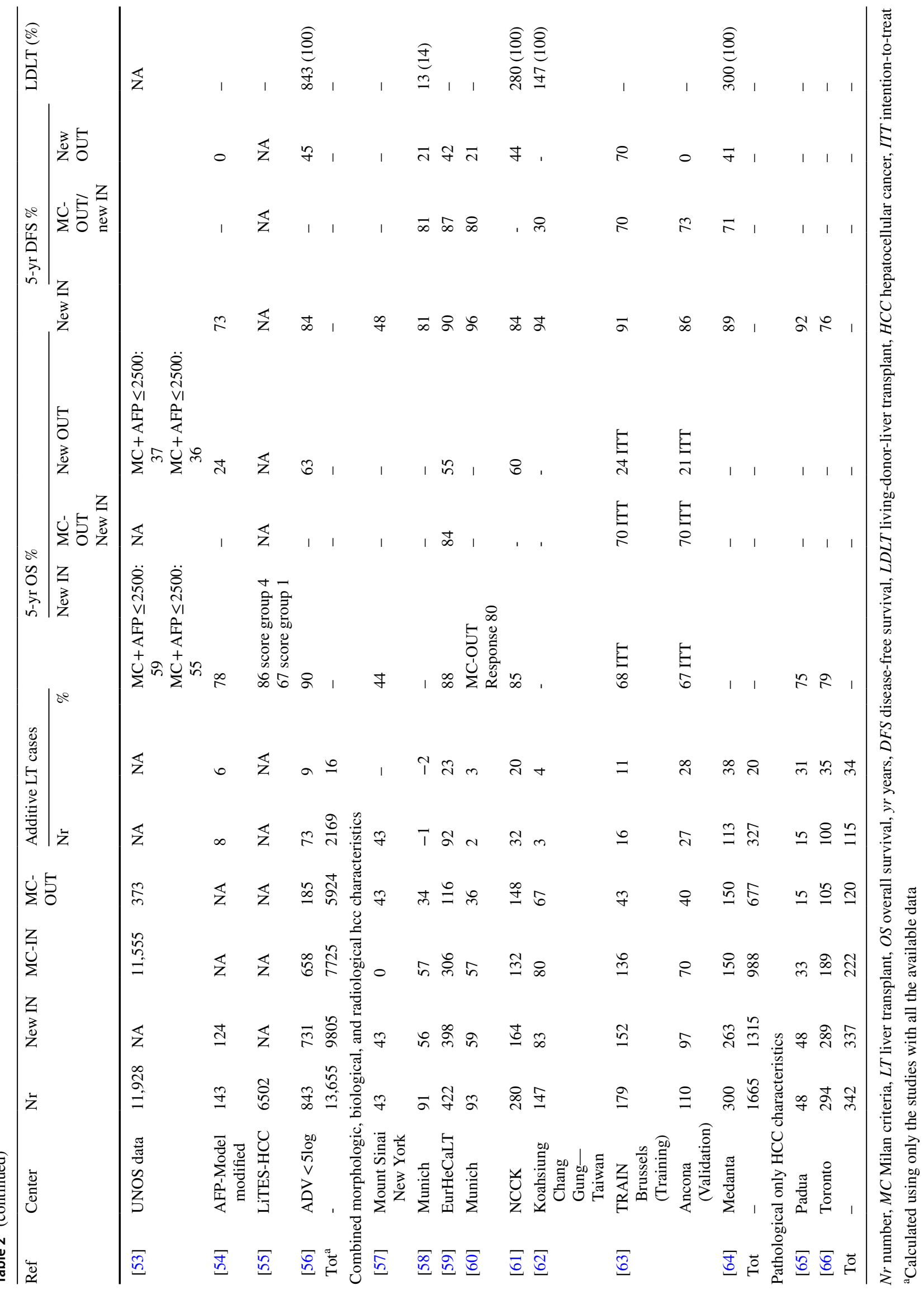


47, 63]. Recently, the radiological response has also been introduced as a useful parameter in selecting HCC cases. For example, the progressive disease after treatment using the mRECIST criteria has been adopted in several studies for predicting the risk of poor post-transplant clinical course $[59,61]$. Also the tracer uptake by the HCC at PETCT scanning has been added as a good prognostic factor in some selection systems [58, 61, 62, 64].

The use of radiological response as a selective tool is the direct consequence of the everyday use of locoregional therapies before transplant, both in the settings of bridging and downstaging [67]. Thanks to the direct effect of these treatments, the selection process has further moved from static to dynamic tumor evaluation. AFP slope $<15 \mathrm{ng} / \mathrm{ml} /$ month $[29,59,63]$ and any morphological response on imaging using the modified-Response evaluation criteria in solid tumors (mRECIST) criteria are favorable prognostic factors [59, 63].

It is interesting to note that almost all the proposed expanded HCC-LT selection systems permit the transplantation of more patients without seriously compromising their long-term outcome. This evidence is also confirmed in the meta-analysis performed, in which very similar recurrence rates were observed comparing the $\mathrm{MC}$ vs. the new criteria, despite $a+28.7 \%$ of transplantable cases was reported using these enlarged systems.

It is of particular interest to note that the DFS rates of patients exceeding the MC but meeting the new selection systems were similar to those obtained in MC. The selection process driven by the new criteria identified a sub-group of MC-OUT patients benefitting from LT. Conversely, if the new selection systems were overruled (new criteria-OUT patients), 5-year DFS was always inferior to $50 \%$, a number corresponding to an oncologically futile transplant procedure. $[68,69]$.

It is difficult to identify the best selection system to use among the proposed ones. The experiences gathered during the last three decades in both deceased and living donor LT in both Western and Eastern centers indicate that the development of a universally acceptable selection system is within reach. The "ideal" HCC-LT score should incorporate scientifically reliable, pre-operatively available,

\section{Percentage of additive transplanted cases respect to MC}

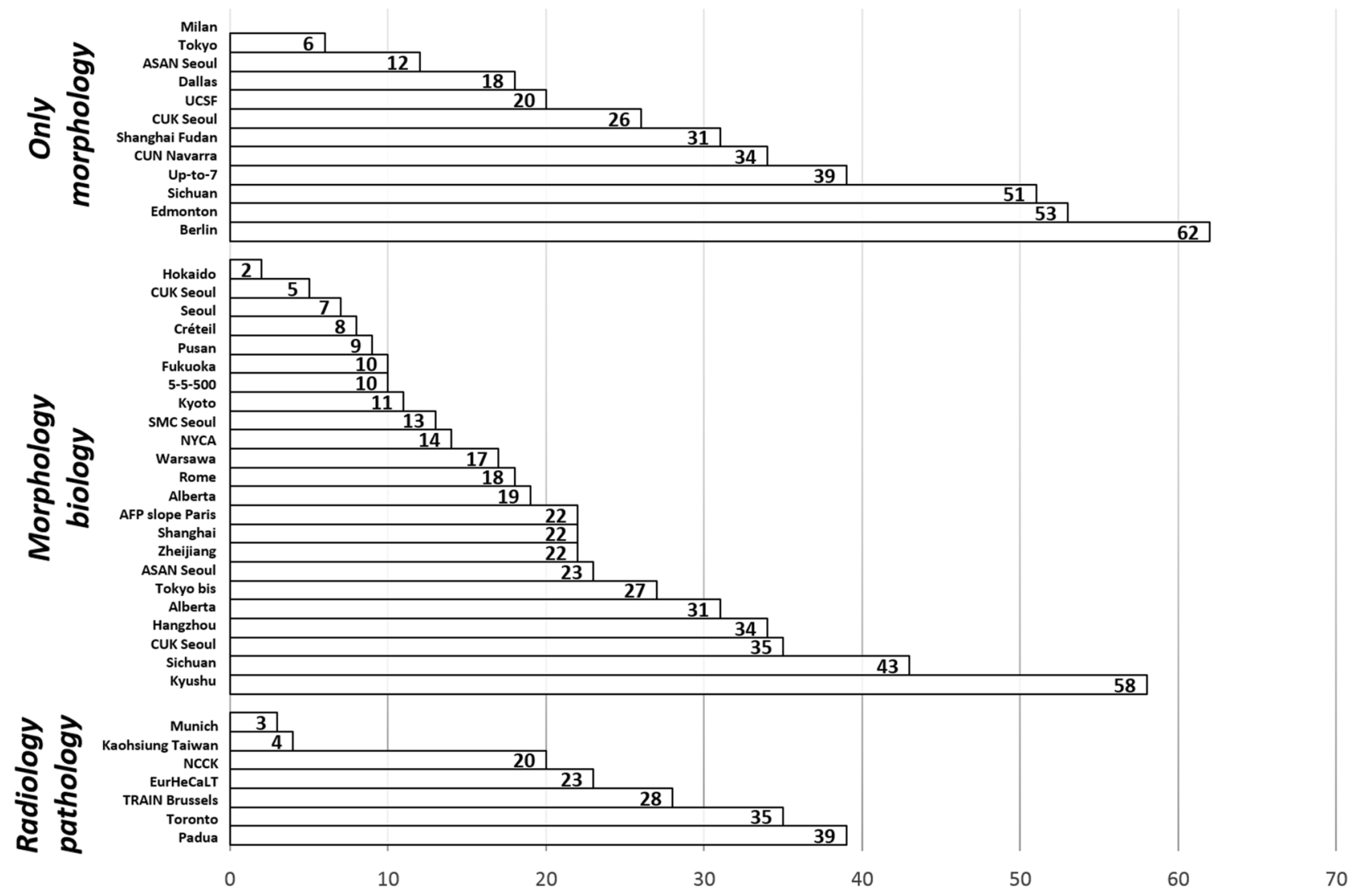

Fig. 3 Percentage of supplementary liver transplantations compared to the Milan criteria when using new expanded criteria 


\section{Five-year overall survival rates}

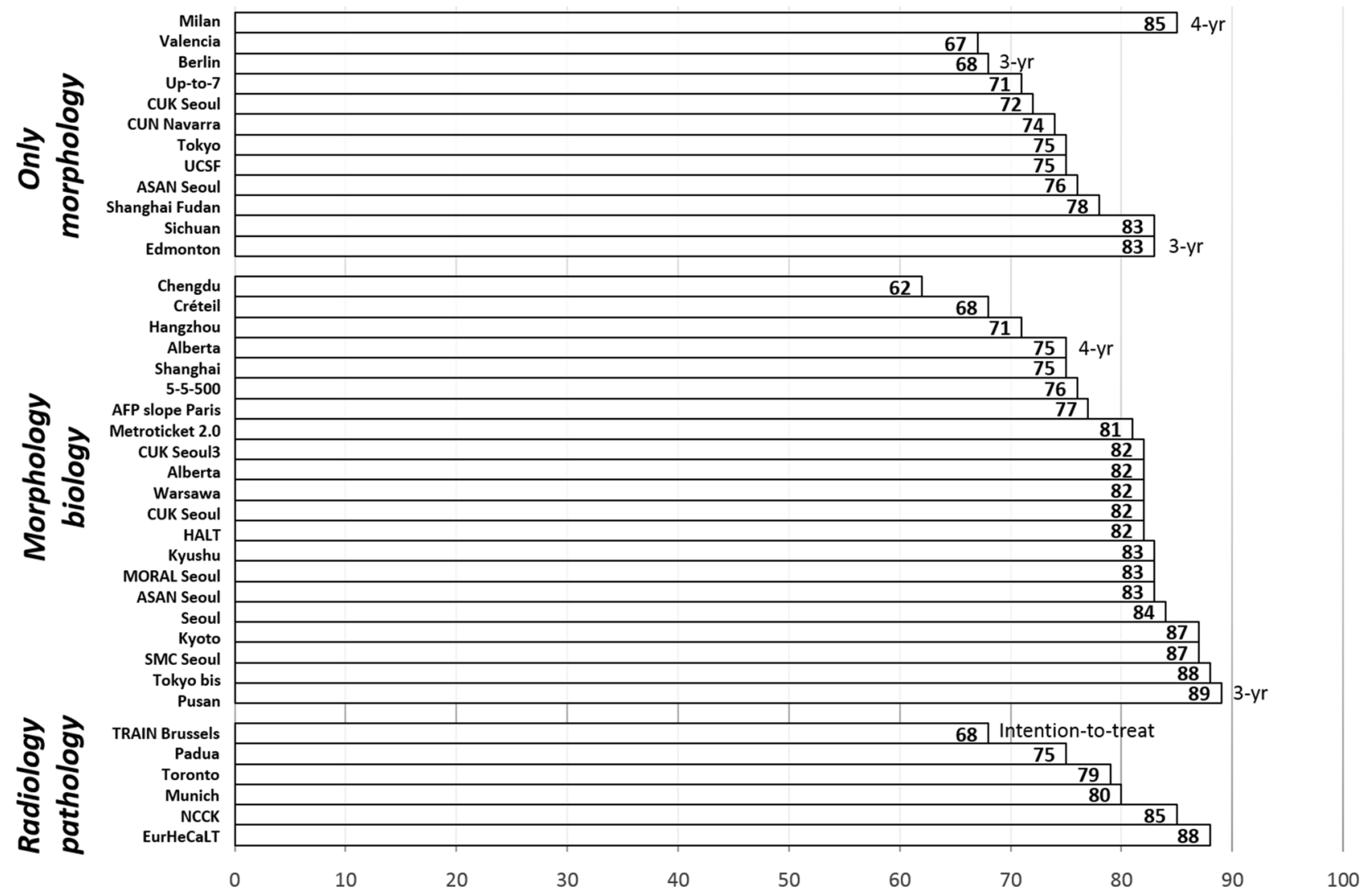

Fig. 4 -year overall survival rates in the different reported HCC criteria

\section{5-year Disease-free survivals}

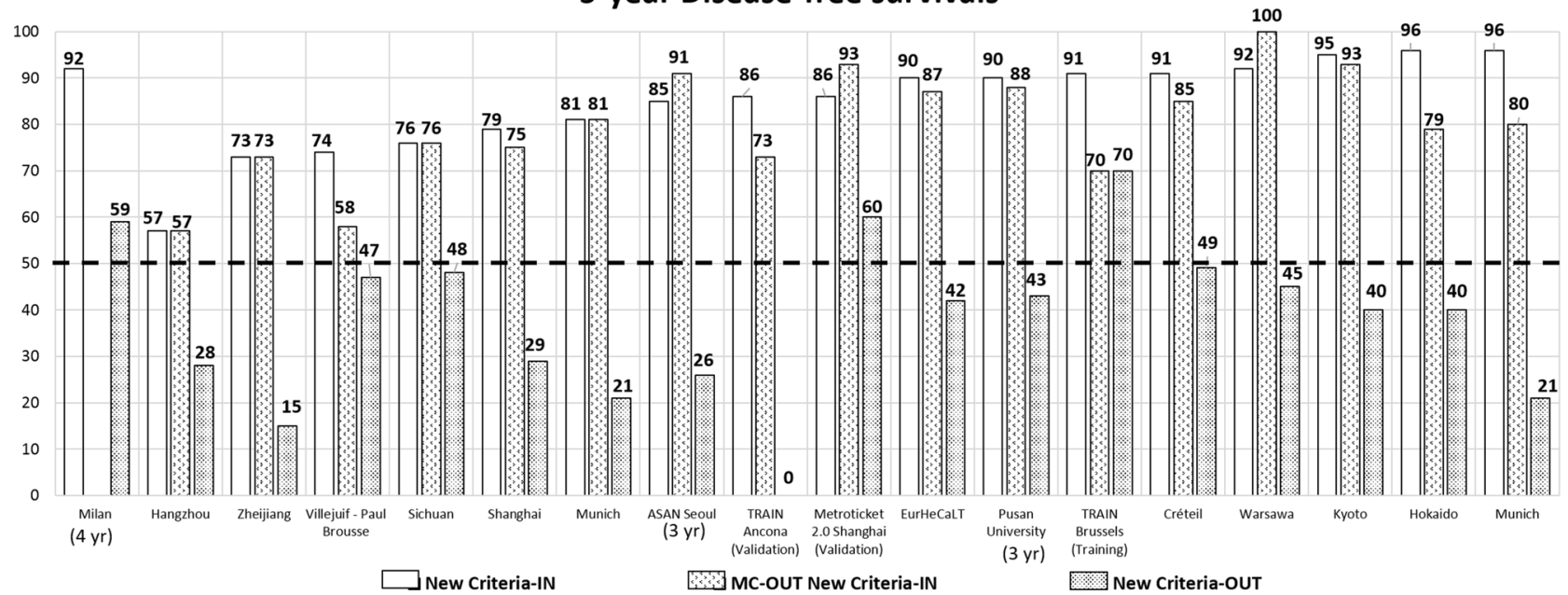

Fig. 5 5-year disease-free survival rates in patients within the Milan criteria, without the Milan criteria but within the new expanded criteria or exceeding the new criteria 


\begin{tabular}{|c|c|c|c|c|c|}
\hline Studies & Est: & imate 195 & 58 C.I.) & Ev/Trt & Ev/Ctr1 \\
\hline Kneteman 2004 & 2.571 & $(0.279$ & $23.700)$ & $5 / 40$ & $1 / 19$ \\
\hline Jonas 2007 & 3.216 & $(0.149$ & $69.455)$ & $3 / 21$ & $0 / 8$ \\
\hline Sugawara 2007 & 0.942 & (0.184, & $4.836)$ & $3 / 72$ & $3 / 68$ \\
\hline Herrero 2008 & 0.992 & $(0.264$, & $3.724)$ & $6 / 71$ & $4 / 47$ \\
\hline Lee 2008 & 0.961 & (0.510, & 1.809) & $23 / 186$ & $21 / 164$ \\
\hline Fan 2009 & 1.151 & $(0.818$ & $1.620)$ & $104 / 570$ & $64 / 394$ \\
\hline Ito 2007 & 0.895 & $(0.123$ & $6.526)$ & $2 / 78$ & $2 / 70$ \\
\hline Taketomi 2009 & 0.843 & $(0.074$, & $9.606)$ & $2 / 85$ & $1 / 36$ \\
\hline Duvoux 2012 & 0.707 & (0.395, & $1.265 \mathrm{~J}$ & $22 / 320$ & $28 / 296$ \\
\hline Choi 2013 & 0.813 & $(0.380$, & $1.738 \mathrm{~J}$ & $14 / 140$ & $16 / 133$ \\
\hline Kashkoush 2014 & 0.369 & $(0.143$, & $0.955)$ & $8 / 88$ & $13 / 61$ \\
\hline Yang 2016 & 0.648 & $(0.211$, & $1.993)$ & $6 / 65$ & $8 / 59$ \\
\hline Grat 2017 & 1.266 & $(0.503$, & $3.187)$ & $12 / 172$ & $8 / 143$ \\
\hline Komberg 2012 & 1.332 & (0.483, & $3.667)$ & $10 / 56$ & $8 / 57$ \\
\hline Komberg 2014 & 1.637 & $(0.586$, & $4.572)$ & $11 / 59$ & $7 / 57$ \\
\hline Cillo 2004 & 1.033 & $(0.163)$, & $6.551)$ & $3 / 48$ & $2 / 33$ \\
\hline DuBay 2011 & 1.193 & (0.659, & $2.161\}$ & $34 / 289$ & $19 / 189$ \\
\hline Overall $\left(I^{\wedge} 2=0 \%, P=0.857\right)$ & 1.006 & $\begin{array}{l}(0.827, \\
0.951\end{array}$ & 1.224) & $268 / 2360$ & $205 / 183$ \\
\hline
\end{tabular}

Favours Expanded Criteria

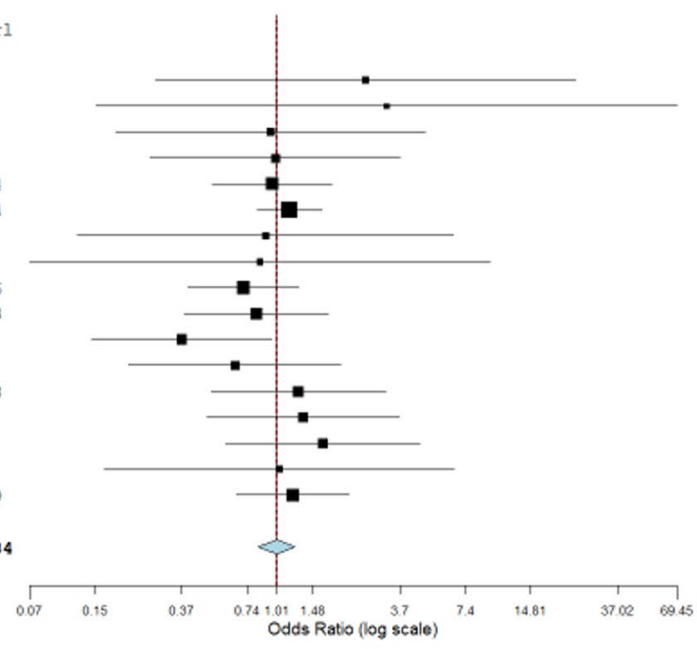

Favours MC

Fig. 6 Forest plot and meta-analysis on the post-transplant recurrence: Milan criteria vs. enlarged selection criteria

easy-to-use, dynamic, morphological plus biological, tumor characteristics.

To further improve the selection process, four different matters need to be explored further. The first relates to the pre-transplant diagnosis of microvascular tumor invasion and poor tumor grading. Due to intra-tumor heterogeneity, tumor aggressiveness is challenging to capture with a biopsy [70]. PIVKA-II, a surrogate marker of vascular invasion, should be systematically implemented in clinical use in Western countries [71]. It is to be expected that radiomics will help to solve this shortcoming in the near future [72].

The second matter relates to the impact of LDLT in the treatment of HCC patients waiting for LT. LDLT not only represents a unique opportunity to increase the allograft pool (necessary to cope with the rising number of HCC patients), but most of all allow exploration of the effect of expanding the HCC inclusion criteria without harming nontumor patients on the waiting list [73]. The role of LDLT in treating HCC patients will become increasingly important, because dropout risk is virtually eliminated [74]. Important in this (ethical) context is also the fact that recent technical developments have turned LDLT from a "high risk, high return" into a "low risk, high return" procedure [75]. These considerations imply that LDLT represents a fertile soil to explore further the role of transplantation in the cure of $\mathrm{HCC}$ patients. The time has come for the Western world to take up this challenge.

The third matter relates to integrating the concept of transplant benefit in HCC patient selection. Transplant survival benefit corresponds to the number of years gained by LT minus the number of years offered by alternative treatments from LT. Intention-to-treat transplant survival benefit adheres to the same concept, considering the gain in life expectancy, but from waiting list registration, thereby taking into consideration any possible therapy from the time of HCC diagnosis [76]. The identification of selection systems based on the concept of benefit should improve the selection process of HCC patients by identifying patients deserving LT and avoiding futile transplants in patients presenting with too advanced or too early tumor burdens.

Finally, any selection system should also consider the immunosuppression load of the HCC liver recipient. Immunosuppression cannot be disregarded in the context of LT for HCC, as it is the most relevant pro-oncogenic factor [77]. This consideration is especially critical when expanding the inclusion criteria, which, by definition, implies a larger tumor burden and a potentially higher risk of recurrence, and when dealing with remaining tumor tissue at the examination of the total hepatectomy specimen [78]. The development of more extensive inclusion criteria should be accompanied by strategies that aim to minimize the immunosuppressive load.

The present study has some limitations. As already underlined, some of the selected papers revealed an uncertain or high risk of bias. This limit is the consequence of the retrospective and non-randomized nature of all studies exploring the role of HCC-LT selection systems. Another limitation relates to the poor homogeneity of the different proposed selection systems, with only a minimal number of studies reporting their external validation. The significant absence of data available in the articles 
strongly limited our meta-analysis. Only 17/66 articles clearly stated the recurrence data required. Indeed, more homogeneous and more detailed studies are required for conducting such an investigation using more significant numbers.

\section{Conclusions}

The development of a widely accepted "comprehensive" HCC-LT selection system is a necessity. To reach this goal, the development of new diagnostic technologies, more comprehensive implementation of living-donor-liver transplantation, and integration of the concept of benefit into the therapeutic scheme of HCC patients will be necessary. All these elements are essential to bring order to the chaos of selection systems and, more importantly, to offer the best possible treatment to the highest possible number of HCC liver patients. Hopefully, the tower of Babel of scores will disappear in the near future.

Author contributions JL, MF, and QL were responsible for the conception, design, analysis, and writing of the study; JL and MF reviewed the papers; JL, MF, and QL were involved with the collection and interpretation of data; JL, MF, and QL participated in data management, review, and editing of the manuscript.

Funding Open access funding provided by Università degli Studi di Roma La Sapienza within the CRUI-CARE Agreement.

\section{Declarations}

Conflict of interest The authors have no conflicts of interest to declare about the present study.

Ethical approval This is a review study which has been conducted in accordance with the ethical standards as laid in the 1964 Helsinki Declaration.

Research involving human participants and/or animals This article does not contain any studies with human participants or animals performed by any of the authors.

Informed consent For this type of study, formal consent is not required.

Open Access This article is licensed under a Creative Commons Attribution 4.0 International License, which permits use, sharing, adaptation, distribution and reproduction in any medium or format, as long as you give appropriate credit to the original author(s) and the source, provide a link to the Creative Commons licence, and indicate if changes were made. The images or other third party material in this article are included in the article's Creative Commons licence, unless indicated otherwise in a credit line to the material. If material is not included in the article's Creative Commons licence and your intended use is not permitted by statutory regulation or exceeds the permitted use, you will need to obtain permission directly from the copyright holder. To view a copy of this licence, visit http://creativecommons.org/licenses/by/4.0/.

\section{References}

1. Starzl TE, Demetris AJ (1990) Liver transplantation: a 31-year perspective. Curr Probl Surg. https://doi.org/10.1016/00113840(90)90017-Y (In "year book medical publishers")

2. Starzl TE (1969) Experience in liver transplantation. WB Saunders Company, Philadelphia, $\mathrm{p} 9$

3. Pichlmayr R, Weimann A, Oldhafer KJ, Schlitt HJ, Tusch G, Raab R (1998) Appraisal of transplantation for malignant tumours of the liver with special reference to early stage hepatocellular carcinoma. Eur J Surg Oncol 24:60-67

4. Bismuth H, Chiche L, Adam R, Castaing D, Diamond T, Dennison A (1993) Liver resection versus transplantation for hepatocellular carcinoma in cirrhotic patients. Ann Surg 218:145-151

5. Mazzaferro V, Regalia E, Doci R, Andreola S, Pulvirenti A, Bozzetti F et al (1996) Liver transplantation for the treatment of small hepatocellular carcinomas in patients with cirrhosis. N Engl J Med 334:693-699

6. Hwang S, Moon DB, Lee SG (2010) Liver transplantation and conventional surgery for advanced hepatocellular carcinoma. Transpl Int 23:723-727

7. Yao FY, Ferrell L, Bass NM, Watson JJ, Bacchetti P, Venook A et al (2001) Liver transplantation for hepatocellular carcinoma: expansion of the tumour size limits does not adversely impact survival. Hepatology 33:1394-1403

8. Mazzaferro V, Llovet JM, Miceli R, Bhoori S, Schiavo M, Mariani L et al (2009) Predicting survival after liver transplantation in patients with hepatocellular carcinoma beyond the Milan criteria: a retrospective, exploratory analysis. Lancet Oncol 10:35-43

9. Sapisochin G, Bruix J (2017) Liver transplantation for hepatocellular carcinoma: outcomes and novel surgical approaches. Nat Rev Gastroenterol Hepatol 14:203-217

10. Hutton B, Salanti G, Caldwell DM, Chaimani A, Schmid CH, Cameron $\mathrm{C}$ et al (2015) The PRISMA extension statement for reporting of systematic reviews incorporating network metaanalyses of health care interventions: checklist and explanations. Ann Intern Med 162:777-784

11. Sterne JAC, Hernán MA, Reeves BC, Savović J, Berkman ND, Viswanathan $M$ et al (2016) ROBINS-I: a tool for assessing risk of bias in non-randomized studies of interventions. BMJ 355:4919

12. Iwatsuki S, Dvorchik I, Marsh JW, Madariaga JR, Carr B, Fung $\mathrm{JJ}$ et al (2000) Liver transplantation for hepatocellular carcinoma: a proposal of a prognostic scoring system. J Am Coll Surg 191(4):389-394

13. Kneteman N, Oberholzer J, Al Saghier M, Meeber G, Blitz M, Ma M et al (2004) Sirolimus-based immunosuppression for liver transplantation in the presence of extended criteria for hepatocellular carcinoma. Liver Transpl 10:1301-1311

14. Jonas S, Mittler J, Pascher A, Schumacher G, Theruvath T, Benckert $C$ et al (2007) Living donor liver transplantation of the right lobe for hepatocellular carcinoma in cirrhosis in a European centre. Liver Transpl 13:896-903

15. Onaca N, Davis GL, Goldstein RM, Jennings JW, Klintmalm GB (2007) Expanded criteria for liver transplantation in patients with hepatocellular carcinoma: a report from the International Registry of Hepatic Tumours in Liver Transplantation. Liver Transpl 13:391-399

16. Sugawara Y, Tamura S, Makuuchi M (2007) Living donor liver transplantation for hepatocellular carcinoma: Tokyo University series. Dig Dis 25:310-312

17. Jl H, Sangro B, Pardo F, Quiroga J, Inarrairaegui M, Rotellar F et al (2008) Liver transplantation in patients with hepatocellular carcinoma across Milan criteria. Liver Transpl 14:272-278 
18. Lee SG, Hwang S, Moon DB, Ahn CS, Kim KH, Sung KB et al (2008) Expanded indication criteria of living donor liver transplantation for hepatocellular carcinoma at one large-volume centre. Liver Transpl 14:935-945

19. Silva M, Moya A, Berenguer M, Sanjuan F, Lopez Andujar R, Pareja E et al (2008) Expanded criteria for liver transplantation in patients with cirrhosis and hepatocellular carcinoma. Liver Transp 14:1449-1460

20. Fan J, Yang GS, Fu ZR, Peng ZH, Xia Q, Peng CH et al (2009) Liver transplantation outcomes in 1,078 hepatocellular carcinoma patients: a multi-centre experience in Shanghai. China J Cancer Res Clin Oncol 135:1403-1412

21. Li J, Yan LN, Yang J, Chen ZY, Li B, Zeng Y et al (2009) Indicators of prognosis after liver transplantation in Chinese hepatocellular carcinoma patients. World J Gastroenterol 15:4170-4176

22. Choi HJ, Kim DG, Na GH, Hong TH, You YK (2012) Extended criteria for living donor liver transplantation in patients with advanced hepatocellular carcinoma. Transplant Proc. 44:399-402

23. Ito T, Takada Y, Ueda M, Haga H, Maetani Y, Oike F et al (2007) Expansion of selection criteria for patients with hepatocellular carcinoma in living donor liver transplantation. Liver Transpl 13:1637-1644

24. Todo S, Furukawa H, Tada M (2007) Extending indication: role of living donor liver transplantation for hepatocellular carcinoma. Liver Transpl 13:S48-54

25. Kwon CH, Kim DJ, Han YS, Park JB, Choi GY, Kim SJ et al (2007) HCC in living donor liver transplantation: can we expand the Milan criteria? Dig Dis 25:313-319

26. Yang SH, Suh KS, Lee HW, Cho EH, Cho JY, Cho YB et al (2007) A revised scoring system utilizing serum alphafetoprotein levels to expand candidates for living donor transplantation in hepatocellular carcinoma. Surgery 141:598-609

27. Xu X, Lu D, Ling Q, Wei X, Wu J, Yan S et al (2016) Liver transplantation for hepatocellular carcinoma beyond the Milan criteria. Gut 65:1035-1041

28. Taketomi A, Sanefuji K, Soejima Y, Yoshizumi T, Uhciyama $\mathrm{H}$, Ikegami $\mathrm{T}$ et al (2009) Impact of des-gamma-carboxy prothrombin and tumour size on the recurrence of hepatocellular carcinoma after living donor liver transplantation. Transplantation 87:531-537

29. Vibert E, Azoulay D, Hoti E, Iacopinelli S, Samuel D, Salloum C et al (2010) Progression of alphafoetoprotein before liver transplantation for hepatocellular carcinoma in cirrhotic patients: a critical factor. Am J Transplant 10:129-137

30. Duvoux C, Roudot-Thoraval F, Decaens T, Pessione F, Badran $\mathrm{H}$, Piardi T et al (2012) Liver transplantation for hepatocellular carcinoma: a model including $\alpha$-fetoprotein improves the performance of Milan criteria. Gastroenterology 143:986-994

31. Lai Q, Avolio AW, Manzia TM, Sorge R, Agnes S, Tisone $G$ et al (2012) Combination of biological and morphological parameters for the selection of patients with hepatocellular carcinoma waiting for liver transplantation. Clin Transplant 26:125-131

32. Choi HJ, Kim DG, Na GH, Han JH, Hong TH, You YK (2013) Clinical outcome in patients with hepatocellular carcinoma after living-donor-liver-transplantation. World J Gastroenterol 19:4737-4744

33. Li C, Wen TF, Yan LN, Li B, Yang JY, Xu MQ et al (2013) Scoring Selection Criteria Including Total Tumour Volume and Pretransplant Percentage of Lymphocytes to Predict Recurrence of Hepatocellular Carcinoma after Liver Transplantation. PLoS ONE 8:e72235

34. Yoshizumi T, Ikegami T, Yoshiya S, Motomura T, Mano Y, Muto $\mathrm{J}$ et al (2013) Impact of tumour size, number of tumours and neutrophil-to-lymphocyte ratio in liver transplantation for recurrent hepatocellular carcinoma. Hepatol Res 43:709-716
35. Na GH, Kim DG, Han JH, Kim EY, Lee SH, Hong TH et al (2014) Inflammatory markers as selection criteria of hepatocellular carcinoma in living-donor liver transplantation. World J Gastroenterol 20:6594-6601

36. Wan P, Zhang J, Long X, Li Q, Xu N, Zhang M et al (2014) Serum levels of preoperative $\alpha$-fetoprotein and CA19-9 predict survival of hepatic carcinoma patients after liver transplantation. European J Gastroenterol Hepatol 26:553-561

37. Wan P, Xia Q, Zhang JJ, Li QG, Xu N, Zhang M et al (2014) Liver transplantation for hepatocellular carcinoma exceeding the Milan criteria: a single-centre experience. J Cancer Res Clin Oncol 140:341-348

38. Shindoh J, Sugawara Y, Nagata R, Kameko J, Tamura S, Aoki T, Sakamoto Y et al (2014) Evaluation methods for pretransplant oncological markers and their prognostic impacts in patient undergoing living donor liver transplantation for hepatocellular carcinoma. Transpl Int 27:391-398

39. Kashkoush S, El Moghazy W, Kawahara G-L, Toso C, Kneteman N (2014) Three-dimensional tumour volume and serum and alphafetoprotein are predictors of hepatocellular carcinoma recurrence after liver transplantation: refined selection criteria. Clin Transplant. 28:728-736

40. Kim JM, Kwon CH, Joh JW, Park JB, Lee JH, Kim GS et al (2014) Expanded criteria for liver transplantation in patients with hepatocellular carcinoma. Trasnplant Proc 46:726-729

41. Xiao GQ, Yang JY, Yan LN (2015) Combining the Hangzhou criteria and the neutrophil-lymphocyte ratio to select patients with hepatocellular carcinoma for liver transplantation. Hepatobiliary Pancreat Dis Int 14:588-595

42. Yang K, Lee TB, Choi BH, Park YM, Ryu JH, Joo DJ et al (2016) Development and applicability of the A-P 200 criteria for liver transplantation for hepatocellular carcinoma. Transplant Proc 48:3317-3322

43. Lee JH, Cho Y, Kim HY, Cho EJ, Lee DH, Yu SJ et al (2016) Serum tumour markers provide refined prognostication in selecting liver transplantation candidate for hepatocellular carcinoma patients beyond the Milan Criteria. Ann Surg 263:842-850

44. Kim SH, Moon DB, Kim WJ, Kang WH, Kwon JH, Jwa EK et al (2016) Preoperative prognostic values of $\alpha$-fetoprotein (AFP) and protein induced by vitamin $\mathrm{K}$ absence or antagonist-II (PIVKA-II) in patients with hepatocellular carcinoma for living donor liver transplantation. Hepatobiliary Surg Nutr 5:461-469

45. Xia W, Ke Q, Guo H, Wang W, Zhang M, Shen Y et al (2017) Expansion of the Milan criteria without any sacrifice: combination of the Hangzhou criteria with the pre-transplant platelet-tolymphocyte ratio. BMC Cancer 17:14

46. Grat M, Wronka KM, Stypulkowski J, Bik E, Krasnodebski M, Masior L et al (2017) The Warsaw proposal for the use of extended selection criteria in liver transplantation for hepatocellular cancer. Ann Surg Oncol 24:526-534

47. Halazun KJ, Najjar M, Abdelmessih RM, Samstein B, Griesemer A, Guarrera JV et al (2017) Recurrence after liver transplantation for hepatocellular carcinoma: a new MORAL to the story. Ann Surg 265:557-564

48. Halazun KJ, Tabrizian P, Najjar M, Florman S, Schwartz M, Michelassi F et al (2018) Is it time to abandon the Milan criteria? Results of a bicoastal US collaboration to redefine hepatocellular carcinoma liver transplantation selection policies. Ann Surg 268:690-699

49. Mazzaferro V, Sposito C, Zhou J, Pinna AD, De Carlis L, Fan J et al (2018) Metroticket 2.0 model for analysis of competing risks of death after liver transplantation for hepatocellular carcinoma. Gastroenterology 154:128-139

50. Shimamura T, Akamastu N, Fujiyoshi M, Kawaguchi A, Morita S, Kawasaki S et al (2019) Expanded living-donor liver 
transplantation criteria for patients with hepatocellular carcinoma based on the Japanese nationwide survey: the 5-5-500 rule - a retrospective study. Transpl Int 32:356-368

51. Firl DJ, Sasaki K, Agopian VG, Gorgen A, Kimura S, Dumronggittigule W et al (2020) Charting the path forward for risk prediction in liver transplant for hepatocellular carcinoma: international validation of HALTHCC among 4,089 patients. Hepatology 71:569-582

52. Ince V, Akbulut S, Otan E, Ersan V, Karakas S, Sahin TT et al (2020) Liver transplantation for hepatocellular carcinoma: Malatya experience and proposals for expanded criteria. J Gastrointest Cancer 51:998-1005

53. Daoud A, Soliman K, Teeter L, Ali H, Graviss EA, Mogawer S et al (2021) Alpha-fetoprotein as a modifier of anatomic criteria for transplantation of HCC patients. Transplant Proc. S00411345(21):00028-00032 (Online ahead of print)

54. Mazzotta AD, Pascale A, Cano L, Rosmorduc O, Allard MA, Sa Cunha A, et al (2021) Number of HCC nodules in patients listed for liver transplantation within Alpha-Fetoprotein Score: a new prognostic risk factor. Transpl Int. Online ahead of print

55. Goldberg D, Mantero A, Newcomb C, Delgado C, Forde KA, Kaplan DE et al (2021) Predicting survival after liver transplantation in patients with hepatocellular carcinoma using the LiTESHCC score. J Hepatol S0168-8278(21):00004 (Online ahead of print)

56. Hwang S, Song GW, Ahn CS, Kim KH, Moon DB, Ha TY et al (2021) Quantitative prognostic prediction using ADV score for hepatocellular carcinoma following living donor liver transplantation. J Gastrointest Surg. https://doi.org/10.1007/s11605-02104939-w (Online ahead of print)

57. Roayaie S, Frischer JS, Emre SH, Fishbein TM, Sheiner PA, Sung $M$ et al (2002) Long-term results with multimodal adjuvant therapy and liver transplantation for the treatment of hepatocellular carcinomas larger than 5 centimeters. Ann Surg 235:533-539

58. Kornberg A, Kupper S, Tannapfel A, Buchler P, Krause B, Witt U et al (2012) Patients with non-18F.fludeoxyglucose- avid advanced hepatocellular carcinoma on clinical staging may achieve longterm recurrence-free survival after liver transplantation. Liver Transpl. 18:53-61

59. Lai Q, Avolio AW, Graziadei I, Otto G, Rossi M, Tisone G et al (2013) Alpha-fetoprotein and modified response evaluation criteria in solid tumours progression after loco-regional therapy as predictors of hepatocellular cancer recurrence and death after transplantation. Liver Transpl 19:1108-1118

60. Kornberg A, Witt U, Matevossian E, Kupper B, Assfalg V, Drzezga A et al (2013) Extended postinterventional tumour necrosis - implication for outcome in liver transplant patients with advanced HCC. PLoS ONE 8:e53960

61. Lee SD, Lee B, Kim SH, Joo J, Kim SK, Kim YK et al (2016) Proposal of new expanded selection criteria using total tumour size and (18)F-fluorodeoxyglucose-positron emission tomography/ computed tomography for living donor liver transplantation in patients with hepatocellular carcinoma: the national cancer Centre Korea criteria. World J Transplant 6:411-422

62. Hsu CC, Chen CL, Wang CC, Lin CC, Yong CC, Wang SH et al (2016) Combination of FDG-PET and UCSF criteria for predicting HCC recurrence after living donor liver transplantation. Transplantation 100:1925-1932

63. Lai Q, Nicolini D, Inostroza Nunez M, Iesari S, Goffette P, Agostini A et al (2016) A novel prognostic index in patients with hepatocellular cancer waiting for liver transplantation: time-radiological-response-alpha-fetoprotein-inflammation (TRAIN) score. Ann Surg 264:787-796

64. Bhangui P, Saigal S, Gautam D, Piplani T, Choudhary N, Chaudhary $\mathrm{R}$ et al (2021) Incorporating tumor biology to predict hepatocellular carcinoma recurrence in patients undergoing living donor liver transplantation using expanded selection criteria. Liver Transpl 27:209-221

65. Cillo U, Vitale A, Bassarello M, Boccagni P, Brolese A, Zanus $G$ et al (2004) Liver transplantation for the treatment of moderately to well-differentiated hepatocellular carcinoma. Ann Surg 239:150-159

66. DuBay D, Sandroussi C, Sandhu L, Cleary S, Guba M, Cattral MS et al (2011) Liver transplantation for advanced hepatocellular carcinoma using poor differentiation on biopsy as an exclusion criterion. Ann Surg 253:166-172

67. Cucchetti A, Serenari M, Sposito C, Di Sandro S, Mosconi C, Vicentin I et al (2020) Including mRECIST in the Metroticket 2.0 criteria improves prediction of hepatocellular carcinoma-related death after liver transplant. J Hepatol. 73:342-348

68. Yao FY (2008) Liver transplantation for hepatocellular carcinoma: beyond the Milan criteria. Am J Transplant 8:1982-1989

69. Petrowsky H, Rana A, Kaldas FM, Sharma A, Hong JC, Agopian VG et al (2014) Liver transplantation in highest acuity recipients identifying factors to avoid futility. Ann Surg 259:1186-1194

70. Friemel J, Rechsteiner M, Frick L, Böhm F, Struckmann K, Egger $\mathrm{M}$ et al (2015) Intratumour heterogeneity in hepatocellular carcinoma. Clin Cancer Res 21:1951-1961

71. Lai Q, Iesari S, Levi Sandri GB, Lerut J (2017) Des-gammacarboxy prothrombin in hepatocellular cancer patients waiting for liver transplant: a systematic review and meta-analysis. Int J Biol Markers 32:e370-e374

72. Ma X, Wei J, Gu D, Zhu Y, Feng B, Liang M et al (2019) Preoperative radiomics nomogram for microvascular invasion prediction in hepatocellular carcinoma using contrast-enhanced CT. Eur Radiol 7:3595-3605

73. Lai Q, Avolio AW, Lerut J, Singh G, Chan SC, Berloco PB et al (2012) Recurrence of hepatocellular cancer after liver transplantation: the role of primary resection and salvage transplantation in East and West. J Hepatol 57:974-979

74. Goldaracena N, Gorgen A, Doyle A, Hansen BE, Tomiyama $\mathrm{K}$, Zhang W et al (2019) Live donor liver transplantation for patients with hepatocellular carcinoma offers increased survival vs. deceased donation. J Hepatol. 70:666-673

75. Iesari S, Inostroza Núñez ME, Rico Juri JM, Ciccarelli O, Bonaccorsi-Riani E, Coubeau L et al (2019) Adult-to-adult living-donor liver transplantation: the experience of the Universite catholique de Louvain. Hepatobiliary Pancreat Dis Int 18:132-142

76. Lai Q, Vitale A, Iesari S, Finkenstedt A, Mennini G, Spoletini $\mathrm{G}$ et al (2017) European Hepatocellular Cancer Liver Transplant Study Group. Intention-to-treat survival benefit of liver transplantation in patients with hepatocellular cancer. Hepatology 66:1910-1919

77. Vivarelli M, Dazzi A, Zanello M, Cucchetti A, Cescon M, Ravaioli M et al (2010) Effect of different immunosuppressive schedules on recurrence-free survival after liver transplantation for hepatocellular carcinoma. Transplantation 89:227-231

78. Schnitzbauer A, Filmann N, Adam R, Bachellier P, Bechstein WO, Becker TH et al (2020) mTOR inhibition is most beneficial after liver transplantationfor hepatocellular carcinoma in patients with active tumors. Ann Surg. https://doi.org/10.1097/SLA.00000 00000004280 (Epub ahead of print)

Publisher's Note Springer Nature remains neutral with regard to jurisdictional claims in published maps and institutional affiliations. 